\title{
Faultlessness of composite enclosing structures with thin-sheet linings and effective thermal insulation
}

\author{
Viktor V. Bobryashov ${ }^{1}$, Viktor M. Bobryashov ${ }^{1}$, Anastasiya Bobryashova ${ }^{2}$ and Nikolay \\ Bushuev $^{3 *}$ \\ ${ }^{1}$ TSNIISK Named After Koucherenko V.A. Research Center of ConstructionJoint Stock Company, \\ 2nd Institutskaya St., 6, Moscow 109428, Russia, \\ ${ }^{2}$ Architectural BureauMezonproekt LLC, Uspenskayaul. 7, Krasnogorsk, Moscow Region, 143409 \\ Russia \\ ${ }^{3}$ Moscow State University of Civil Engineering, Yaroslavskoe shosse, 26, Moscow, 129337, Russia
}

\begin{abstract}
Fencing composite structures with thin-sheet metal cladding and effective thermal insulation are widely used. They are especially effective in hard to reach, remote, seismic areas, in areas with harsh climates. There is a problem of estimating the real random loading of snow, wind, ice, temperature loads and others according to Roshydromet, when the strength, heat engineering, dielectric, and other structural parameters are random and changes in which from the allowable area lead to failures.The paper provides an assessment of the reliability of enclosing structures of buildings based on quantitative signs of impacts (wind, snow and permanent), as well as the results of statistical evaluation of factory acceptance tests. This paper discusses to exhaust the resource - the strength of the middle layer of the structure during shear.
\end{abstract}

\section{Introduction}

On the basis of acceptance tests, we distinguish statistical quality control of products by qualitative (suitable, defective) and quantitative characteristics (according to the values of one or several parameters) $[1,2,3]$.

Fencing composite structures with effective thermal insulation are multifunctional, multi-element systems. Fiberglass, glass fiber laminates, aluminum, steel and various nonmetallic materials such as asbestos cement, gypsum board, chipboard, cement chipboards, etc. are used as outer layers for them. Perlitoplastbeton, polymeric foams, basalt fiber plates, rigid and semi-rigid mineral are used as thermal insulation. The connection of the outer layers with thermal insulation, as a rule, is carried out with polymer adhesives. Depending on the constructive solution, they can be frameless, frame or with discrete links along the contour. Designs can be bearing, self-supporting, mounted. The scope of enclosing structures is extremely diverse. They are especially effective in remote, seismic areas, in areas with a harsh climate, as well as in areas where specific indicators are needed - radio transparency, bulk and surface electrical resistance, high resistance to

\footnotetext{
*Corresponding author: bush_ni@mail.ru
} 
aggressive media, increased resistance to pulsed electrical voltages, high efficiency emissions, etc.

Special scientific problems arise in connection with the wide range of applications for enclosing structures. The main one is the problem of estimating the real random loading, as well as the resistance of stochastic loading in conditions when the parameters of structures are random variables (accuracy, heat engineering, strength, dielectric, etc.). Resistance to impacts are random processes, the change (emissions) of which from the permissible quality area leads to failures $[4,5]$.

\section{Literature review}

As a result of variable loading, the impact of climatic factors and special loads during operation, there is a gradual evolution of the properties of materials, including a decrease in the bearing capacity of structures. Therefore, it is necessary to create design models for the operation of enclosing structures, taking into account the random nature of loads, impacts and the stochastic nature of the strength of materials and signs of indicators that lead to failures of non-mechanical origin.

The problem of accidental loading brings to the fore the question of the normative reliability of models of operation, safety factors, the reliability index. It should be borne in mind that probabilistic calculations are expedient and demonstrative, with reliability within $\mathrm{P}=0,99-0,999[4,5,6]$.

In this study, an assessment of the reliability of quantitative characteristics, as for the effects (loads), and for the strength. The essence of the scientific problem of assessing the reliability of composite enclosing structures, which are characterized by mechanical failures (Group I and II limit states) and failures of non-mechanical origin (partial), is considered in detail. These include: the exhaustion of resistance to heat transfer, corrosive wear, as well as the reduction of the standard values of sound insulation, increased moisture and air tightness. Sanitary-hygienic and other indicators not considered in this work are subject to separate consideration.

As practice has shown, none of the problems of probabilistic and deterministic reliability (reliability, durability, maintainability and maintainability) cannot be solved without fulfilling the main scientific thesis (triad) - reliability is laid during design, ensured during manufacture, maintained and restored during operation, is at all stages of the life cycle of structures. At the same time systematic work should be carried out to maintain and restore reliability.

Thus, the assessment of reliability of layered structures, taking into account the random nature of the effects and random response (carrying capacity), is an important scientific practical problem [7].

This study with the use of dimensionless probabilistic parameters of load and strength is a priority. The statement of its goals, tasks is based on the format of safety standards $[8,9]$, EN standards [10], etc. It follows in its essence the provisions specified in these documents, realizing them before practical engineering use. However, it cannot be assumed that reliability calculations are exhausted by this study. Apparently, there is still a lot of significant scientific work to be done to develop the probabilistic ideology proposed in this study for capital construction projects - composite enclosing structures with effective thermal insulation. 


\section{Research Methods}

The following sets out the basis for estimating the probability of failure-free operation of walling structures with thin-sheet linings and effective thermal insulation, using dimensionless parameters of impacts (loads) and strength.

The distribution of annual maxima of wind and snow loads is assumed by the double exponential Gumbel law of the I-th type [5,6,11,12,13]

$$
\begin{aligned}
& P_{x}=\exp [-\exp ((\alpha-q) / b)] \\
\text { Forwind load } & P_{\mathrm{qB} 1}=\exp \left[-\exp \left(\left(\alpha-\mathrm{q}_{\mathrm{B} 1}\right) / \mathrm{b}\right)\right] \\
\text { forsnow load } & \mathrm{P}_{\mathrm{qs} 1}=\exp \left[-\exp \left(\left(\alpha-\mathrm{q}_{\mathrm{s} 1}\right) / \mathrm{b}\right)\right]
\end{aligned}
$$

where $\mathrm{q}_{\mathrm{B} 1}, \mathrm{q}_{\mathrm{s} 1}$ - respectively wind and snow loads;

$\alpha$ and $\mathrm{b}$ - parameters of distributions, which are determined by the mean values of loads $(\bar{x})$ and their standard deviations $(\hat{x})[12,13]$ :

$$
\begin{aligned}
\bar{x} & =\alpha+0,577 b \\
\hat{x} & =1,283 b \\
b & =\hat{x} / 1,283 \\
\alpha & =\bar{x}-0,577 b
\end{aligned}
$$

In (7) the free parameter " $\alpha$ " is related to the Gumbel distribution mode [12, 13], the parameter "b" (6) is related to the dispersion of distribution statistics. Note that the ratio $b / \alpha$ corresponds approximately to the ratio $\hat{\mathrm{x}} / \overline{\mathrm{X}}$.

The value of loads $[11,12,13]$, using $(6,7)$, we obtain:

where $\mathrm{q}_{(1)}$ is the value of the annual maximum loads;

$$
\begin{aligned}
& \mathrm{q}_{(1)}=\alpha-\mathrm{b} \ln \left(-\ln \mathrm{P}_{\mathrm{q}}\right), \\
& \mathrm{q}_{(\mathrm{n})}=\mathrm{q}+\mathrm{b} \ln \mathrm{n},
\end{aligned}
$$

$\mathrm{q}_{(\mathrm{n})}$ - calculated value of loads at their repeated influence;

$\mathrm{P}_{\mathrm{q}^{-}}$the security of loads when they are single exposure $\mathrm{P}_{\mathrm{q}}=0,98$ [8-10].

Procedure for carrying out annual maximum loads to dimensionless form.For example, for VII wind region $\overline{\mathrm{X}}=850 \mathrm{~Pa} ; \hat{\mathrm{x}}=204 \mathrm{~Pa}$ from table.1, according to $(6,7)$ have $\alpha=758,26$ $\mathrm{Pa} ; \mathrm{b}=159 \mathrm{~Pa}$.

The load $\mathrm{q}_{(1)}$ by (8) is: $q_{(1)}=\alpha-b \ln \left(-\ln P_{q}\right)=758,26+159 \cdot 3,9=1378,66 \mathrm{~Pa}$.

In accordance with (1) carry out the procedure of bringing loads to dimensionless form, using the values of $\mathrm{P}_{\mathrm{q} 1 \mathrm{v}}$ by (2), and the parameters: $\alpha$ and $\mathrm{b}$ by $(6,7)$.

The function of dimensionless load $\mathrm{F}_{\mathrm{q}}$ for VII region has the form $[6,11,12]$ :

$$
F_{q\left(q_{1} v\right)}=\exp \left(-\exp \left[-\frac{1378,66}{159}\left(q_{i}-\frac{758,76}{1378,66}\right)\right]\right)=\exp \left(-\exp \left[-8,67\left(q_{i}-0,55\right)\right]\right)
$$

After performing the above procedure for other wind regions, we obtain the distribution function of the annual maxima $F_{q\left(q_{1} v\right)}$ in dimensionless values for areas I-VII (table.1). The data of different weather stations given in $[12,14]$ are used for $\bar{x}, \hat{x}$ values.

Table 1. Distribution functions of annual maxima $F_{q\left(q_{1} v\right)}$ in dimensionless values for wind regions I-VII

\begin{tabular}{|c|c|c|c|c|c|c|c|}
\hline \multirow{2}{*}{$\begin{array}{c}\text { Wind } \\
\text { districts }\end{array}$} & \multicolumn{9}{|c|}{ Parameter values } \\
\cline { 2 - 8 } & $\overline{\boldsymbol{x}}, \mathbf{P a}$ & $\widehat{\boldsymbol{x}}, \mathbf{P a}$ & $\begin{array}{c}\boldsymbol{C}_{\boldsymbol{S}}, \\
\text { wind }\end{array}$ & $\boldsymbol{\alpha}, \mathbf{P a}$ & $\boldsymbol{b}, \mathbf{P a}$ & $\boldsymbol{P}_{\boldsymbol{q}}$ & $\boldsymbol{F}_{\boldsymbol{q}\left(\boldsymbol{q}_{\mathbf{1}} \boldsymbol{v}\right)}$ \\
\cline { 2 - 9 } & $\mathbf{1}$ & $\mathbf{2}$ & $\mathbf{3}$ & $\mathbf{4}$ & $\mathbf{5}$ & $\mathbf{6}$ & $\mathbf{7}$ \\
\hline $\mathrm{I}$ & 200 & 88 & 0,44 & 160,4 & 68,6 & & $\exp ^{-\exp \left[-6,24\left(q_{i}-0,375\right)\right]}$ \\
\hline
\end{tabular}




\begin{tabular}{|c|c|c|c|c|c|c|c|}
\hline II & 270 & 100 & 0,37 & 225,0 & 77,9 & \multirow{6}{*}{0,98} & $\exp ^{-\exp \left[-6,79\left(q_{i}-0,425\right)\right]}$ \\
\hline III & 360 & 115 & 0,32 & 308,2 & 89,6 & & $\exp ^{-\exp \left[-7,34\left(q_{i}-0,462\right)\right]}$ \\
\hline IV & 480 & 149 & 0,31 & 413,1 & 115,0 & & $\exp ^{-\exp \left[-7,46\left(q_{i}-0,477\right)\right]}$ \\
\hline $\mathrm{V}$ & 600 & 156 & 0,26 & 529,8 & 121,6 & & $\exp ^{-\exp \left[-8,26\left(q_{i}-0,527\right)\right]}$ \\
\hline VI & 700 & 189 & 0,27 & 665,0 & 147,3 & & $\exp ^{-\exp \left[-8,41\left(q_{i}-0,536\right)\right]}$ \\
\hline VII & 850 & 204 & 0,24 & 758,3 & 159,0 & & $\exp ^{-\exp \left[-8,67\left(q_{i}-0,55\right)\right]}$ \\
\hline
\end{tabular}

Note: $\mathrm{C}_{\mathrm{S}}$ is load variability

Similarly, we will perform the procedure of reducing snow loads to a dimensionless form for snow regions I-VIII. The results are shown in Table 2, with the data for [12] being used for the values $\bar{x}, \hat{x}$

Table 2. Distribution functions of annual maxima $F_{q\left(q_{1} s\right)}$ in dimensionless values for snow regions I-VIII

\begin{tabular}{|c|c|c|c|c|c|c|c|}
\hline \multirow{2}{*}{$\begin{array}{c}\text { No. } \\
\mathbf{p p}\end{array}$} & \multirow{2}{*}{$\begin{array}{c}\text { Snow } \\
\text { districts }\end{array}$} & \multicolumn{6}{|c|}{ Parameter values } \\
\cline { 3 - 8 } & $\overline{\boldsymbol{x}}, \mathbf{P a}$ & $\widehat{\boldsymbol{x}}, \mathbf{P a}$ & $\boldsymbol{C}_{\boldsymbol{S}}$ & $\boldsymbol{\alpha}, \mathbf{P a}$ & $\boldsymbol{b}, \boldsymbol{P a}$ & $\boldsymbol{F}_{\boldsymbol{q}\left(\boldsymbol{q}_{\mathbf{1}}\right)}$ \\
\cline { 3 - 8 } & $\mathbf{1}$ & $\mathbf{2}$ & $\mathbf{3}$ & $\mathbf{4}$ & $\mathbf{5}$ & $\mathbf{6}$ \\
\hline 1 & I & 357 & 125 & 0,35 & 301 & 97 & $\exp ^{-\exp \left[-7,58\left(q_{i}-0,407\right)\right]}$ \\
\hline 2 & II & 714 & 250 & 0,35 & 602 & 195 & $\exp ^{-\exp \left[-6,90\left(q_{i}-0,445\right)\right]}$ \\
\hline 3 & III & 1080 & 326 & 0,37 & 841 & 254 & $\exp ^{-\exp \left[-7,21\left(q_{i}-0,45\right)\right]}$ \\
\hline 4 & IV & 1400 & 528 & 0,38 & 1162 & 412 & $\exp ^{-\exp \left[-6,72\left(q_{i}-0,42\right)\right]}$ \\
\hline 5 & V & 1790 & 752 & 0,42 & 1449 & 591 & $\exp ^{-\exp \left[-6,35\left(q_{i}-0,385\right)\right]}$ \\
\hline 6 & VI & 2140 & 880 & 0,41 & 1780 & 623 & $\exp ^{-\exp \left[-6,75\left(q_{i}-0,422\right)\right]}$ \\
\hline 7 & VII & 2500 & 1056 & 0,42 & 2025 & 823 & $\exp ^{-\exp \left[-6,36\left(q_{i}-0,38\right)\right]}$ \\
\hline 8 & VIII & 2800 & 1200 & 0,43 & 2260 & 935 & $\exp ^{-\exp \left[-6,32\left(q_{i}-0,382\right)\right]}$ \\
\hline
\end{tabular}

Note. In Tables 1 and 2, the same load security is assumed to be $\mathrm{P}_{\mathrm{q}}=0.98$ for single and multiple exposures, which corresponds to an average repetition period of 50 years[10, 25] or $P_{q}=\left(1-\frac{1}{50}\right)=$ 0,98 [14].

\section{Results of Research, discussion}

Next we give the calculation of the dimensionless snow load.

Procedure for bringing strength to dimensionless valuesFurther, the strength is dimensionless according to the above algorithm when replacing the symbols $\bar{x}, \hat{x}$ with the resistance $\bar{R}, \hat{R}$.

Based on the factory's mass acceptance tests, we determine the average strength value $(\bar{R})$ and its standard deviation $(\hat{R})$. Set a dimensionless value of $\bar{r}$ and $\hat{r}$ :

$$
\bar{r}=\frac{\bar{R}}{R^{P}} ; \quad \hat{r}=\frac{\widehat{R}}{R^{P}} .
$$

In (11) $\mathrm{R}^{\mathrm{P}}$ is the calculated strength value determined by the following rule:

$$
R^{P}=\frac{R^{\mathrm{H}}}{\gamma_{m}},
$$

where: normative value $\mathrm{R}^{\mathrm{n}}$ equals $\mathrm{R}^{\mathrm{n}}=\bar{R}\left(1-x_{1} C_{R}\right)$;

$\gamma_{\mathrm{m}}$ - material safety factor, $\gamma_{m}=\frac{\left(1-\chi_{1} C_{R}\right)}{1-\chi_{2 C_{R}}}$; 


$$
C_{R} \text { - Variability of strength equal to } C_{R}=\frac{\sigma_{R}}{\bar{R}}
$$

$\sigma_{R}$ - standard deviation;

$\chi_{1}, \chi_{2}$ - quantile values for normative and calculated resistances, respectively, accepted depending on the given "security" (confidence probability). For example, in [8] the "security" value for $\mathrm{R}^{\mathrm{n}}$ is set for all materials not less than $\mathrm{P}=0,95 \chi_{1}=1,64$ quantile. It is not normalized for design resistances in [8]. According to the recommendations [11, 12] "security" is entered equal to $\mathrm{P}=0,995 \ldots 0,99865$, quantile values are equal to $\chi_{1}=$ 2,$58 ; \chi_{2}=3,0$ respectively. For steel, stone, aluminum and other building structures the value of "security" is given in the corresponding codes of rules on the structure.

It should be noted that the value (size) of variability $R^{P}, \chi_{2}$ in norms [8] is not defined by introduction of coefficient. Authors gave offers on quantitative, economically reasonable $\chi_{2}$ depending on the period of repetition of influences, the index of reliability and variability in [15]. When taking into account the duration of exposure and the environment should be in the calculated value of RP to enter the coefficients of working conditions, taking into account changes in the parameters of strength (bearing capacity), according to the special recommendations of TSNIISK in accordance with (16).

$$
R^{P}=R^{H} \cdot m_{d u r} \cdot m_{t} \cdot m_{w} \cdot m_{i}
$$

The coefficients $m_{d u r}, m_{t}, m_{w}, m_{i}$ represent long-term strength (endurance), the effect of temperature, humidity, resistance to aggressive media, and others.

The probability of failure-free operation according to $[8,15,16,17]$ is set as follows:

$$
\bar{Q}<\bar{R}
$$

Here $\bar{Q}, \bar{R}$ are the average values of load and strength, respectively, which are independent or correlated among themselves. That is, always the resistance $\bar{R}$ to impacts should be greater than the load $\bar{Q}$.

In the method of limit states, inequality (17) has the form:

$$
\gamma_{n} \bar{Q}^{P} \leq \bar{R}^{P}
$$

where $\gamma_{n}$ is the reliability coefficient of responsibility, taken equal to $1.1 ; 1.0 ; 0.9$ by [7].

The best proposals for the coefficient of responsibility are given in [18].

Dividing (17) into (18), we get

$$
\frac{1}{\gamma_{n}} \cdot \bar{q}<\bar{r}
$$

Since the load and strength have different probability distributions, we bring them to the standard normal distribution:

$$
q^{*}=F^{(-1)}\left[\Phi_{q\left(q_{1}\right)}\right]
$$

where $F^{(-1)}$ is the inverse function of the probability integral of the form

$$
\begin{aligned}
F & =\frac{1}{\sqrt{2 \pi}} \int_{-\infty}^{\infty} \exp \left(-\frac{1}{2} x^{2}\right) d x \\
r^{*} & =\frac{q_{i}}{\gamma_{n} \cdot \hat{r}}-\frac{\bar{r}}{\hat{r}}=\frac{1}{\hat{r}}\left(\frac{q_{i}}{\gamma_{n}}-\bar{r}\right)
\end{aligned}
$$

The reliability index $\beta$ is determined by the expression $[6,10] \beta=\sqrt{\left(q^{*}\right)^{2}+\left(r^{*}\right)^{2}}$. Here, the values of $q^{*}, r^{*}$ are calculated from (20) and (22).

Then the probability of failure-free operation according to $[8,10]$ is equal to

$$
P=\frac{1+F_{(\beta)}}{2},
$$

where $F_{(\beta)}$ is the function of the normal standard integral distribution.

Or the probability of failure $\mathrm{W}$ :

$$
W=1-P
$$

Impacts (loads) are determined according to the results of the assessment of real climate observations of Roshydromet, submitted to TSNIISK [14, 19]. When assessing impacts, the scientific thesis is often ignored that they are random temporal processes, as it is extensively interpreted by the authors in their works, and not random variables. Adjustment 
of impact assessments (loads) is constantly going on sometimes because of volitional decisions and aspirations to follow the provisions of the Eurocodes, ISO, EN norms, which, in fact, are not harmonized with the current norms in the Russian Federation. In some cases, they have not been tested in the design of real buildings and structures.

In connection with the above, a refined scientific interpretation of the snow load for region III is proposed, in contrast to [25], since its values are further used for the calculation $(\bar{Q}=1043,2 \mathrm{~Pa})$. In accordance with [14], the snow load parameters for the III area based on the results of annual maximums for 94 years, according to Roshydromet mean value $\overline{\mathrm{Q}}=1043,2 \mathrm{~Pa}$, standard deviation $\widehat{\mathrm{Q}}=358,3 \mathrm{~Pa}$, coefficient of variation (variability) $\mathrm{C}_{\mathrm{Q}}=0,343$.

Using these data, the estimation of free parameters according to Gumbel [13] was carried out $\alpha=882 \mathrm{~Pa}, \mathrm{~b}=365 \mathrm{~Pa}, C_{S}=0,41$ with "security" $P_{q}=0,98$, according to the formulas (4-7).

The distribution function of the dimensionless load $\Phi_{q_{\left(q_{1}\right)}}$ for the source data

is equal to $q_{(1)}=\alpha-b \ln \left(-P_{q}\right)=882+279 \cdot 3,9=1970 \mathrm{~Pa}$,

Therefore: $\Phi_{q_{\left(q_{1}\right)}}=\exp \left(-\exp \left[-7,06\left(\frac{q_{i}}{\gamma_{n}}-0,447\right)\right]\right)$

A more accurate load value calculated by the double exponential Gumbel law with the number of annual maxima $\mathrm{N}=94$ is equal to [14]:

$$
\begin{gathered}
q_{94}=\bar{Q}+\frac{\sigma}{\sigma_{N}}\left(y-\bar{y}_{n}\right) ; \\
q_{94}=1043,2+\frac{358,3}{1,203}(-3,9+0,5592)=2038,019 \mathrm{~Pa}
\end{gathered}
$$

In (26), the values $\mathrm{y}=3,9 ; \bar{y}_{N_{94}}=0,5592 ; \sigma_{N}=1,203$ were adopted according to [13].

In [25] given the calculated value of the snow load for the III area $S_{w}=1500 \cdot 1,4=2100$ $\mathrm{Pa}$, which differs from the values $(26)$ by $3,04 \%$. These deviations are caused by the fact that the norms [25] reflect averaged information for snow region III. It was established that the variability of the snow load for the Moscow region according to [14] is $C_{Q}=0,26 \div$ 0,33 (in the forest) and $C_{Q}=0,30 \div 0,40$ (in the field). $C_{Q}$ affected by the protection from external influences and openness of tracking stations.

The strength (bearing capacity) during shear of structures was established as a result of a generalization of acceptance tests of 960 samples for the period 1976-2018. according to Russian GOST21562-76,GOST 23486-79 and GOST 22695-77, developed, approved, implemented by the authors. When testing panel samples with dimensions $(1100 \times 250 \times \mathrm{H})$ $\mathrm{mm}$ with, signs of destruction were failure due to resource exhaustion - shear strength $(\tau)$. Note that the failures of enclosing structures can be of mechanical and non-mechanical origin, as was noted earlier. The samples obtained during acceptance tests were presented in the form of a statistical variational distribution series (Table 3). It was the basis for the calculation of experimental and theoretical laws and statistics of the distribution.

Table 3. Statistical variation range of strength distribution when shifting the middle layer of polyurethane foam panels (PUR)

\begin{tabular}{|c|c|c|c|c|c|c|c|c|c|}
\hline$\tau_{i}$ & 1,1 & 1,5 & 1,89 & 2,28 & 2,68 & 3,07 & 3,46 & 3,86 & 4,25 \\
\hline$n_{i}$ & 30 & 117 & 318 & 315 & 144 & 25 & 7 & 1 & 3 \\
\hline
\end{tabular}

Note. $\tau_{i}$ - mid-range of shear strength, $\mathrm{kgf} / \mathrm{cm}^{2}\left(\approx 10^{5} \mathrm{~Pa}\right)$, $n_{i}$ - frequency range

Distribution statistics are determined by the multiplicative method (products) using the conditional zero, taken from the shear strength values in the middle of the intervals $\tau=$ $2.28 \mathrm{kgf} / \mathrm{cm}^{2}\left(\approx 10^{5} \mathrm{~Pa}\right)$ with $n_{i}=315$. It is useful as a conditional zero to take the values of 
a series of distribution with a maximum frequency (maximum density). It corresponds to the distribution mode of $\mathrm{M}_{\mathrm{o}}: \mathrm{M}_{\mathrm{o}}=2,09 \mathrm{kgf} / \mathrm{cm}^{2}\left(\approx 10^{5} \mathrm{~Pa}\right)$.

The main statistics calculated according to Table 3 and their parameters are given below. The mean value is $\bar{\tau}=2,1195 \mathrm{kgf} / \mathrm{cm}^{2}\left(\approx 10^{5} \mathrm{~Pa}\right)$; standard deviations $\hat{\tau}=0,454$ $\mathrm{kgf} / \mathrm{cm}^{2}\left(\approx 10^{5} \mathrm{~Pa}\right)$; variability $\mathrm{C}_{\tau}=0,194 ;$ initial moments $\mathrm{m}_{1}=-0,425 ; \mathrm{m}_{2}=1,514 ;$ $\mathrm{m}_{3}=-1,13 ; \mathrm{m}_{4}=8,189$; central moments $\mu_{2}=1,33, \mu_{3}=0,64 ; \mu_{4}=7,84$; main points $\mathrm{r}_{3}=$ 0,$415 ; r_{4}=4,38$; asymmetry $\mathrm{A}=0,415$; kurtosis $\mathrm{E}=1,38$. They are used to calculate the reliability (table. 5).

In work on the experimental results of shear strength $(\tau)$, various probabilistic theoretical models were studied [2, 4, 6, 12, 20, 21, 22], including

Gauss-Laplace:

$$
\begin{gathered}
f(\bar{\tau} ; \hat{\tau})=(\hat{\tau} \sqrt{2 \pi})^{-1} \exp \left[-\frac{\left(\tau_{i}-\bar{\tau}\right)^{2}}{2(\hat{\tau})^{2}}\right] \\
f(\bar{\tau} ; \hat{\tau})=(0,454 \cdot 2,505)^{-1} \exp \left[-\frac{\left(\tau_{i}-2,12\right)^{2}}{2(0,454)^{2}}\right] \\
f(2,12 ; 0,454)=0,879 \cdot \exp \left[-\frac{\left(\tau_{i}-2,12\right)^{2}}{0,412}\right]
\end{gathered}
$$

Gram-Charlier (type A):

Pearson Type IV:

$$
\begin{gathered}
\tilde{n}_{j}=\frac{n}{\sigma} f_{A_{(x)}}-\frac{r_{3}}{6} f_{(x)}^{(3)}+\frac{\left(r_{4}-3\right)}{24} f_{(x)}^{(4)} \\
\tilde{n}_{j}=\frac{960}{0,454} f_{A_{(x)}}-\frac{0,415}{6} f_{(x)}^{(3)}+\frac{(4,383-3)}{24} f_{(x)}^{(4)} \\
\tilde{n}_{j}=\frac{n}{\sigma} f_{A_{(x)}}-0,069 f_{(x)}^{(3)}+0,057 f_{(x)}^{(4)}(28)
\end{gathered}
$$

$$
\begin{aligned}
& \tilde{n}_{j}=\tilde{n}_{0}\left(1+\frac{x^{2}}{l^{2}}\right)^{-q} \exp \left(-\operatorname{varctg} \frac{\chi}{l}\right) \\
& \tilde{n}_{j}=292,2\left(1+\frac{x^{2}}{9,474}\right)^{-5,284} \exp \left(2,193 \cdot \operatorname{arctg} \frac{\chi}{3,078}\right)
\end{aligned}
$$

Logarithmically - normal:

$$
\begin{gathered}
f(\tau)=\frac{M}{\sigma} \exp ^{-\left(\frac{\lg \tau_{i}-0,736}{2 \sigma^{2}}\right)} \\
f(\tau)=\frac{M}{0,19} \exp ^{-\left(\frac{\lg \tau_{i}-0,736}{0,072}\right)} \\
f(\tau)=\frac{\tau^{i}}{i !} \exp ^{-\tau},
\end{gathered}
$$

Poisson distribution where: $\tau=2.575 \mathrm{kgf} / \mathrm{cm}^{2}\left(\approx 10^{5} \mathrm{~Pa}\right)$.

The results of calculations of the shear strength of the PUR for various theoretical the oretical models are shown in Table 4. 
Table 4. Summary table of the probability distributions of the shear strength PUR

\begin{tabular}{|c|c|c|c|c|c|c|c|}
\hline \multirow{2}{*}{ No. } & \multirow{2}{*}{$\begin{array}{c}\boldsymbol{\tau}_{\boldsymbol{i}}, \mathbf{2} \\
\mathbf{k g f} / \mathbf{c m}^{\mathbf{2}} \\
(\mathbf{\sim 1 0} \mathbf{5} \mathbf{P a})\end{array}$} & $\begin{array}{c}\text { Experi } \\
\text { mental } \\
\text { frequencies }\end{array}$ & $\begin{array}{c}\text { Gram- } \\
\text { Charlier } \\
\text { TypeA }\end{array}$ & $\begin{array}{c}\text { Gram- } \\
\text { Charlier } \\
\text { TypeB }\end{array}$ & $\begin{array}{c}\text { Pearson } \\
\text { Type IV }\end{array}$ & $\begin{array}{c}\text { Gauss- } \\
\text { Laplace }\end{array}$ & Puasson \\
\hline$\bullet$ & $\mathbf{0 , 7 1}$ & $\mathbf{0}$ & $\mathbf{0}$ & $\mathbf{0}$ & $\mathbf{2 , 4 6}$ & $\mathbf{0}$ & $\mathbf{0}$ \\
\hline 1 & 1,11 & 30 & 15,85 & 13,46 & 19,86 & 27,62 & 73,11 \\
\hline 2 & 1,50 & 117 & 109,51 & 160,73 & 120,74 & 130,86 & 188,25 \\
\hline 3 & 1,89 & 318 & 347,32 & 303,56 & 331,50 & 292,95 & 242,37 \\
\hline 4 & 2,29 & 315 & 326,67 & 278,87 & 310,43 & 309,89 & 208,04 \\
\hline 5 & 2,68 & 144 & 101,28 & 151,92 & 126,84 & 154,90 & 133,92 \\
\hline 6 & 3,07 & 25 & 35,61 & 48,73 & 34,92 & 36,59 & 68,97 \\
\hline 7 & 3,47 & 7 & 15,43 & 5,49 & 8,68 & 4,08 & 29,60 \\
\hline 8 & 3,86 & 1 & 2,50 & 2,66 & 2,24 & 0,22 & 10,89 \\
\hline 9 & 4,25 & 3 & 0,15 & 1,19 & 0,63 & 0,01 & 3,50 \\
\hline & $\Sigma$ & 960 & 954,31 & 958,91 & 958,29 & 957,11 & 958,66 \\
\hline
\end{tabular}

Table 5 shows an example of determining the probability of failure-free operation with a given security $\mathrm{P}_{\mathrm{q}}$ for layered structures with effective thermal insulation of polyurethane foam.

Table 5. Estimation of probability of failure-free operation

\begin{tabular}{|l|c|c|c|}
\hline \multicolumn{1}{|c|}{ Parameters } & Designation & Formula & Value \\
\hline $\begin{array}{l}\text { The coefficient taking into } \\
\text { account the possible damage } \\
\text { to human life and health }\end{array}$ & $\gamma_{n_{1}}$ & & 1 \\
\hline $\begin{array}{l}\text { The coefficient taking into } \\
\text { account the possible material } \\
\text { damage }\end{array}$ & $\gamma_{n_{2}}$ & & 1 \\
\hline $\begin{array}{l}\text { Coefficient of responsibility } \\
\text { for the intended purpose }\end{array}$ & $\gamma_{n}$ & $\gamma_{n}=\gamma_{n_{1}} \cdot \gamma_{n_{2}}$ & 1 \\
\hline $\boldsymbol{a}$ parametervalue & $a$ & $a=1.2825 / \widehat{R}$ & 3,11 \\
\hline $\boldsymbol{u}$ parametervalue & $u$ & $u=\bar{R}-0.5772 / a$ & 1,93 \\
\hline $\begin{array}{l}\text { The standard value of } \\
\text { strength, restored by the } \\
\text { double exponential law of } \\
\text { Gumbel, 105 Pa }\end{array}$ & $R_{\text {Гум } I}^{H}$ & $R_{G u m I}^{H}=u-\frac{1}{a}\left[\ln \left(-\ln \left(1-P_{q}\right)\right)\right]$ & 1,49 \\
\hline Weightratio (sensitivity) & $\alpha_{R}$ & $\alpha_{R}=\hat{R} / \sqrt{\hat{R}^{2}+\hat{Q}^{2}}$ & 0,00115 \\
\hline Required Reliability Index & erf & $c=\alpha_{R} \cdot \operatorname{erf} \beta$ & 3 \\
\hline $\boldsymbol{c}$ coefficient value with & $c$ & & 0,00346 \\
\hline
\end{tabular}




\begin{tabular}{|l|c|c|c|}
$\begin{array}{l}\text { The standard value of } \\
\text { strength, restored by the } \\
\text { double exponential law of } \\
\text { Gumbel, } 105 \mathrm{~Pa}\end{array}$ & $F(c)$ & & 0,5014 \\
\hline The value of the parameter q* & $q^{*}$ & $q^{*}=F^{-1}\left[\Phi_{q(q)}\right]$ & 2,054 \\
\hline The value of the parameter $\mathbf{r}^{*}$ & $r^{*}$ & $r^{*}=\frac{1}{\hat{r}}\left(\frac{q_{i}}{\gamma_{n}}-\bar{r}\right)$ & $-2,664$ \\
\hline $\begin{array}{l}\text { Estimated value of reliability } \\
\text { index }\end{array}$ & $\beta$ & $\beta=\sqrt{\left(q^{*}\right)^{2}+\left(r^{*}\right)^{2}}$ & 3,364 \\
\hline Probabilityofuptime & $P$ & $\mathrm{P}=\frac{\Phi(\beta)+1}{2}$ & 0,9998 \\
\hline Renouncement & $W$ & $W=1-P$ & 0,00019 \\
\hline
\end{tabular}

According to the results of evaluations of factory acceptance tests, a high probability of failure-free operation $\mathrm{P}=0,9998$ was obtained with a reliability index $\beta=3,364$.

\section{Conclusion}

The results of factory acceptance tests of layered structures with effective thermal insulation were evaluated, and on the basis of them, procedures for determining dimensionless loads, dimensionless strength (bearing capacity) were developed for the first time. In the procedure of reducing loads to a dimensionless type, it was assumed that its average value for snow region III is $\bar{Q}=1043,2 \mathrm{~Pa}$, the value of the standard deviation of the load $\hat{Q}=358,3 \mathrm{~Pa}$, load variability $\mathrm{C}_{\mathrm{Q}}=0,343$, "security" loads $\mathrm{P}_{\mathrm{q}}=0,98$. In the procedure of reducing the strength to the dimensionless type, it was assumed that the average strength value at the acceptance tests $(\mathrm{N}=960$ samples $) \bar{R}=2,12 \mathrm{kgs} / \mathrm{cm}^{2}\left(\approx 10^{5}\right.$ $\mathrm{Pa})$, the value of the standard deviation: $\mathrm{R}=0,413 \mathrm{kgf} / \mathrm{cm}^{2}\left(\approx 10^{5} \mathrm{~Pa}\right)$, coefficient of variation $C_{R}=0,195$, "o carelessness "of the normative value of strength $P_{(1)}=0,95$.

Statistical estimates of effects and strength were obtained - the mean value, standard deviation, variability, asymmetry, kurtosis and probabilistic of Gumbel's effects and strength according to five probabilistic theoretical models.

In estimating a given reliability, the probabilistic load models according to Gumbel's double exponential type I law and the Gauss probabilistic strength (bearing capacity) are taken as the basis. They were introduced on the basis of statistical studies of the authors, taking into account the criteria of agreement according to Kolmogorov and Pearson.

The increased reliability of composite structures with thin-sheet linings and effective thermal insulation when the resource is exhausted in the middle layer of insulation (shear strength) is shown $\mathrm{P}=0,9998$ and the failure probability $\mathrm{W}=0,00019$.

Evaluation of acceptance tests by quantitative characteristics of materials, structures showed that the adopted technological processes (continuous, bench) ensure the stability (stability) of all quality parameters specified in [23]. At the same time, the quality indicators exceed the best foreign analogues of the firms Hösch (FRG), Metekno (Italy), Parock (Finland), Sekmer (France), etc., when used as thermal insulation polyurethane foam polyuane foam, polyethylene foam PIR.

Conclusions, provisions, requirements, approved, stated in the article, can be extended to other objects of research, where factory acceptance tests are carried out.

The study showed that at the preliminary design stage, it is possible to determine the probability of failure-free operation of structures, having a priori results of dimensionless loads determined from the data given in [25], as well as using the results of acceptance tests 
of the manufacturers of the structures, determining their dimensionless values. The calculation should be based on the "security" of standard values of at least $\mathrm{P}=0,95$ and the "security" of calculated values of at least $\mathrm{P}=0,99$.

To obtain minor failures, it is necessary to fully reduce the variation (variability) of the carrying capacity, strength of materiafs and pre-set the safety factor for the average values of annual maximums of loads and carrying capacity. Very important preliminary deterministic calculations of the stress state of composite laminated structures.

\section{References}

1. RD-50-705-91 Planning and statistical processing of static fatigue test results. - M., 1992.

2. Shor YA.B., Kuz'min F.I. Tables for the analysis and control of reliability. - M .: Soviet Radio, 1968.

3. Belyayev YU.K. Probabilistic sampling methods. - M .: Science, 1975.

4. Chamis K. Composite materials. Analysis and design of structures. - M .: Mechanical Engineering. - Volume 8, Part 2, 1978.

5. Application of the methods of probability theory and reliability theory in the calculations of structures. - M .: SI, 1971

6. Shpete G. Reliability bearing constructions.- M .: SI, 1994.

7. Federal Law of December 30, 2009 No. 384-FZ Technical Regulations on the Safety of Buildings and Structures.

8. GOST 27751-2014 Reliability of building structures. The main provisions.

9. GOST R ISO 2394-2016 Construction structures. Basic principles of reliability..

10. EN 1990 Eurocode. Basics of building design.

11. Rzhanitsyn A.R. The theory of calculation of building structures for reliability. - M.: stroiizdat, 1978, $239 \mathrm{p}$.

12. Raiser V.D. Methods of the theory of reliability in the problems of valuation, design parameters of building structures. - M .: SI, 1986, $192 \mathrm{p}$.

13. Gumbel E. Statistics of extreme values. - M .: Mir, 1965.

14. NazarovYu.L., Lebedeva I.V., Popov N.A. Regional rationing of snow loads in Russia // Construction mechanics and structural design. - 2006, №3.

15. Bobryashov V.M., BatrakV.Ye.,Bobryashov V.V., Bushuev N.I. Evaluation of the impact of loading time on the quality parameters (creep under shear) of thermal insulation in thin-sheet metal fencing structures, taking into account the probability distributions of their shear strength // Bulletin NRC "Construction" / Research on the Theory of Structures. - Issue 3 (18), 2018.. - Vypusk 3(18), 2018, p. 6-12.

16. Bondar' S.V., Panferov K.V., Potapov YU.N., Bobryashov V.M. Experimental studies of polyurethane foam creep under shear / Tr. TSNIISK: Scientific research in the field of improving the quality of enclosing laminated structures. - M .: stroiizdat, 1982, p. 131-137.

17. Andrei Glasunov, Viktor Bobryashov, Nikolay Bushuev: Building Platforms of Polymer Matrix Based Composite Construction Materials for Transportation Facilities// International Scientific Conference Energy Management of Municipal Transportation Facilities and Transport EMMFT 2017// Advances in Intelligent Systems and Computing/ - Vol.692.

18. Otstavnov V.A., Smirnov A.F., Rayzer V.D. Accounting for the responsibility of buildings and structures in the norms of design of building structures // Construction mechanics and calculation of structures. - 1981. - p.11-14.

19. Lebedeva I.V. The history of the development of domestic standards of snow loads // Bulletin of the SRC “Construction. - No.3 (14), 2017. 
20. Bobryashov V.M., Bobryashov V.V., Bushuev N.I. Probabilistic assessment of random loading of materials and energy saving of enclosing building structures // Bulletin SIC "Construction" / Research on the theory of structures. - No.3 (14), 2017.

21. Sukhina K.N., Pshenichkina V.A., Zhurbina E.N. Engineering herald Don. - №4, 2015.

22. Znamensky E.M. Improving the valuation of the design characteristics of structural elements // Proc. scientific works TSNIISK: Development and improvement of wooden structures. - M., 1989.

23. GOST 4.220-82 System of indicators of product quality. Lightweight fencing panels with foam insulation. The nomenclature of indicators.

24. GOST 27.502-83 Reliability in engineering. The system of collecting and processing information.Planning Observations.

25. SP 20.13330-2016 Loads and impacts. 